\title{
INFLUENCE OF THE PRODUCT CONTEXT OF USE ON A HYBRID SPORT-HEALTH SEMANTICS
}

\author{
A. Millet ${ }^{1,2,3, \otimes}$, A. Abi Akle ${ }^{1}$ and J. Legardeur ${ }^{1,2}$ \\ 1 École Supérieure des Technologies Industrielles Avancées, France, ${ }^{2}$ IMS - Laboratoire de l'Intégration du \\ Matériau au Système, France, ${ }^{3}$ Sport-Controle, France \\ $\triangle$ a.millet@estia.fr
}

\begin{abstract}
Products appearances are made of design choices influencing the way products are perceived. Products semantics is a methods used to understand and anticipate this phenomena. Nowadays, consumers consider sport products not only as "sport" but also as "health" products. Designers may then develop them as "sport-health" products. However, perception of "sport-health" products may vary according to the need to fit sport or health context of use. We present in this paper our experimental approach to understand the influence of sport and health contexts on "sport-health" semantics.
\end{abstract}

Keywords: product design, user-centred design, Kansei engineering

\section{Introduction}

Designers develop innovative products by and with consumers and/or users in sport product design (Lüthje, 2004; von Hippel, 2009). Sport product design can then be assimilated to a User Centred Design approach (Wilson et al., 2017). It involves designers to understand and translate all users' needs into products, from the functional level to the pleasure level of needs (Jordan, 2003).

During design process of sports' product, there is sometimes a twofold objective: the need to improve sport's performances but also the need to keep or improve the user's health (INSEP, 2015). Sport's products are then not designed only as sport's products but also as health ones (Stefanyshyn and Wannop, 2015). However, sport products and health products are designed in a different way and therefore perceived differently by consumers. Indeed, health products are described with words like "rudimentary" or "dull" (Trujillo et al., 2017) while sports products are described as "bold" or "showy" (Green and Chattaraman, 2019). Designers call these words used by consumers semantics. Considering the product as a communication media between designers and users, product semantics tries to explain which messages a product expresses or represents (Petiot and Yannou, 2004).

In literature we can find semantics for sport products like shoes (Shieh and Yeh, 2015; Green and Chattaraman, 2019) or sportswear (Marsac et al., 2018). We notice semantics used to health products too, like wellness products (Masagué and Macià, 2015), products for elderly (Guo et al., 2018) or a neonatology ward (Trujillo et al., 2017). However, there is no specific work concerning semantics for sport-health hybrid products developed for both sport and health products. In a previous work, we attempted to define a "sport-health" semantic space from sport semantics and health semantics by considering the design of a hybrid "sport-health" product (Millet et al., 2019). As results, we identified 32 semantic descriptors adapted to describe a "sport-health product". However, designers need to take 
into account contexts of use to convey a meaning through product (Krippendorff, 2005; Schütte et al., 2008). A product with a sport-health semantics may be developed by taking into account the sport context or health context. Designers need to observe "sport-health" semantics regarding these contexts of use in order to anticipate the meaning to convey. It assumes then that, despite a "sport-health" semantics, designers are not yet guided for this purpose. This assumption motivates us to understand what is the influence of sport and health contexts on sport-health semantics?

In this paper, we describe our approach to answer this question. We first introduce product semantics (Section 2). Afterwards, we show the experimental design realized (Section 3). Finally, we present our results and their analyses (Section 4).

\section{Product semantics in design}

Nowadays customers no longer buy products, they buy experiences through products (Norman, 2007; Hassenzahl, 2010). While developing products, designers must not only take into account the functional aspects but also the affective and emotional aspects of products (Demirbilek and Sener, 2003; Jordan, 2003; Chitturi, 2009). Designers should therefore integrate and anticipate the affective function of products within the design process. In User Centred Design approach, we can observe methods for this purpose like Kansei/Affective Engineering (Nagamachi, 1989; Schütte et al., 2008). They allow engineers/designers to anticipate design elements like colours, shapes or textures to convey meanings through products called semantics (Demirbilek and Sener, 2003). As defined by Krippendorff and Butter (1984), product semantics is the "study of symbolic qualities of man-made shapes in the cognitive and social context of their use". Product semantics allows to understand how users interpret the appearance, the use and the context of products.

In design, products semantics can be used to define and explore semantic spaces of a product domain. Words defining the product domain compose a semantic space. As example, a semantic space for cars' realm can be composed of words like luxury, familial, sportive or economy. These words, called semantics, could be extracted from various media like magazines, scientific literature or directly from experts (Schütte et al., 2008). Results of the collect of semantics can be summarized within a heuristic map as illustrated in box on the left in Figure 1 (Wang et al., 2018). Another use of products semantics in design consists on mapping products. Each product realm presents a semantic space characterizing the products. Products of the targeted domain can then be mapped regarding these words composing the semantic space (illustrated in middle box in Figure 1). As example, Kongprasert et al. (2008) used the semantic map to compare the positioning of handbags perception between French and Thai people. Cluster of products are then identifiable and specific features of products can be extracted to get inspiration for the design process. Bouchard and Omhover (2016) used the semantic mapping in addition to mood boards to this end as well. In a Conjoint Trends Analysis approach, they argue that identifying markets trends in the early phases of the design process allows to better anticipate and guide the product development thereafter. Products semantics can be used in a third way as well. Osgood (1952) developed a Semantic Differential method allowing to evaluate products and describe it with specific criteria. A product semantic profile can be realized by applying this method with semantics as criteria (illustrated in the right box in Figure 1). Semantic profile can help to visualize the strength and weakness of products and to compare them regarding all words composing the semantic space at the same time.

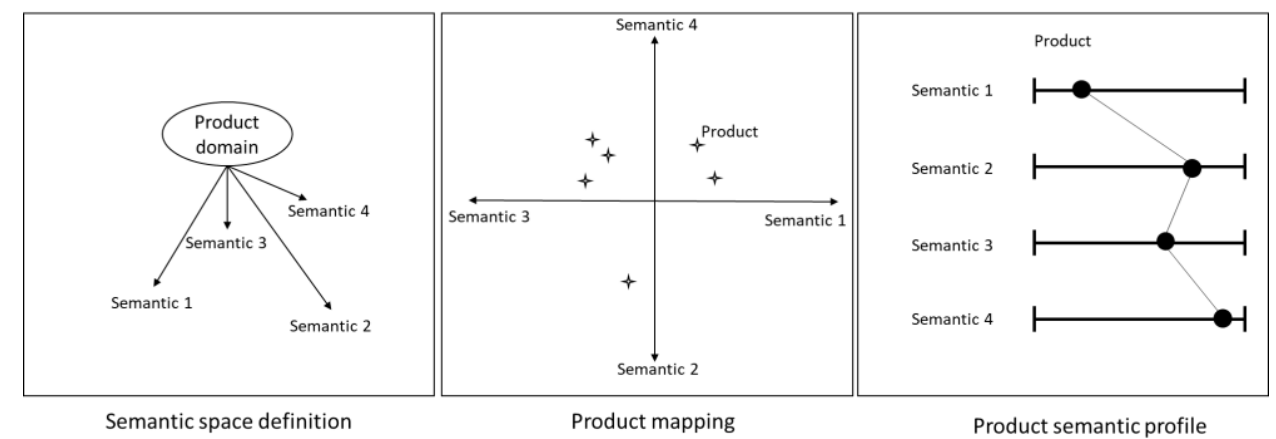

Figure 1. Representation of products semantic use in design 
In regards with the three usage of products semantics in design, the definition of the semantic space represents then the basis of products semantics. However, product contexts of use mainly influence the semantic of products (Krippendorff, 2005). It is then necessary to consider its influence while defining the semantic space. In this paper, we take a closer look to sport-health products. We consider sport and health as product contexts of use. In a previous work, we extracted a sport-health semantics list (Millet et al., 2019). However, we did not observe how they are impacted by sport and health contexts of use. This lack motivates us to confront sport-health semantics with both sport and health contexts in order to understand their impact on semantics.

Following parts of this paper present our experimental approach to observe the influence of sport and health contexts on sport-health semantics.

\section{Experimental design}

To answer our research question, we conducted interviews combined with a card sorting method. Interviews are commonly used to explore opinion or mental representations of a studied population indepth (Lallemand and Gronier, 2018). We decided to interview designers and engineers who are experts in sport, health and sport-health products' design. According to Ahmed et al. (2003), we consider them as experts if they gather at least 8 years of experiences in a specific field.

Interviews were divided into three steps (illustrated in Figure 2):

1. Sport-health product selection

2. Sport-health semantics selection

3. Sport-health semantics evaluation

In the first step, the sport-health product selection, we invite participants to think about products they consider as sport-health products. We choose to adapt a card sorting approach to help them for this task. Card sorting approach presents the advantages of being simple to understand and to keep participant stimulated during the task (Lallemand and Gronier, 2018). Participants should first sort cards on which product picture are depicted into three categories: sport, health and sport-health products. Pictures which are not categorized as sport-health pictures are then put aside for the following parts of the interview (see Step 1 in Figure 2). Participants could thereafter focus on considered sport-health products' cards and sort them into three new categories: sport-health products for sport, sport-health products for health and sport-health products without context distinction. A total of 85 product cards were created and on each of them is printed a picture of sport, health or sporthealth products. All pictures were collected from web sites specialized of product distributors. The first step of the interview ends not only with a visual overview of a sport-health product but also with a categorization of sport-health considered pictures regarding contexts of use.

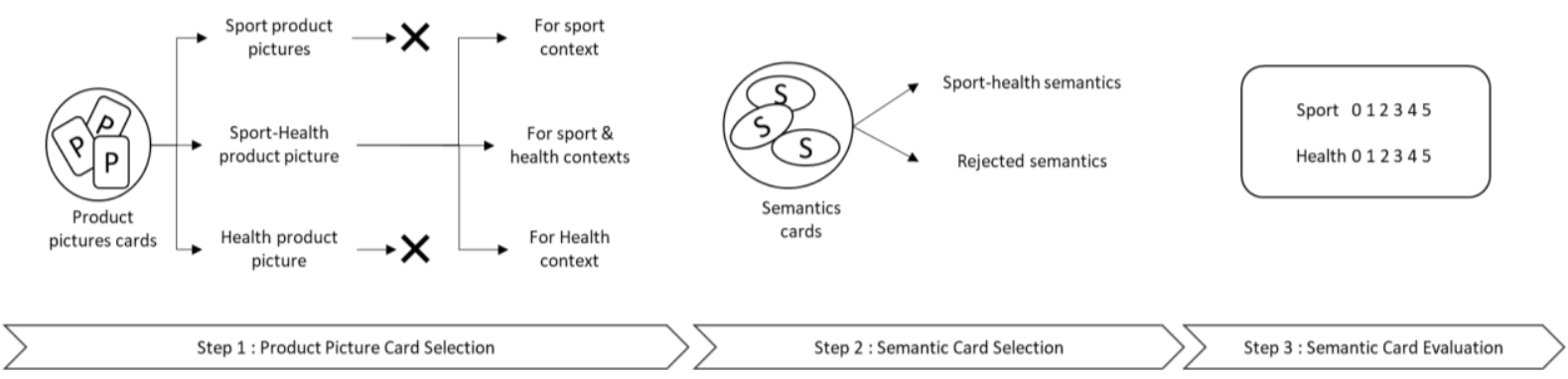

Figure 2. Proceeding of the interview

During the second step of the interview, sport-health semantic selection, we aim to identify a semantic space of sport-health products. We invite participants to suggest and to sort semantics descriptors of a sport-health product to this end. Visual overview previously realized is used as support to help them for this task. To realize the sport-health semantic space, we provide them cards on which semantics descriptors are printed and blank cards on which they can write to suggest new semantics. They must select among semantic cards which one are adapted to a sport-health context. Semantics non selected as adapted to sport-health context are then put aside for the step 3 of the interview (see Step 2 in 
Figure 2). We created a set of 96 cards composed of 86 semantics extracted from literature in our previous work (Millet et al., 2019) and 10 blank cards to write on. This step ends with a visual and semantic overview of a sport-health product.

In the last step of the interview, sport-health semantics evaluation, we aim to evaluate how sport and health contexts of use influence the sport-health semantics. For this purpose, we dispose two six-point scales with a range from 0 to 5 on the back of each blank and semantic cards (see Step 3 in Figure 2). One scale allows to evaluate semantic descriptors with health context of use and the other one with sport context. Participants must evaluate each semantics card they generated and selected on these two scales. 0 means that the semantic descriptor presents no relations with sport or health context of use and 5 a tough relation. The interview ends when participants finished to evaluate all semantics cards defined in step 2 (selected and written).

We limited the duration of interview to one hour. It was motivated by the fact that interviews were realized during their duty time and in order to minimize the risks of cognitive overload.

\subsection{Sport and health semantics scores}

Each participant evaluates during the interview a sample of the semantic cards proposed, i.e. cards they associate to sport-health products realm, in order to observe the influence of the product context on semantics. We collect then all sport and health scores of each semantic card evaluated for each participant. Furthermore, we may observe consensus or dissensus between participants about a semantic descriptor. We decide therefore to take this into account by calculating an agreement indicator.

For this purpose, we first calculate standard deviations of scores on sport scale SDsport $_{i}$ (see Equation 1) and on health scale $S D$ health $h_{i}$ (see Equation 2) for each semantic selected descriptor i. We apply afterward Equation (3) to obtain a measure of overall variability. Finally, we propose an agreement indicator Iagree (see Equation 4). Higher is Iagree, stronger is the consensus between participants. If a semantic card is evaluated by only one participant, $\|\mathrm{SD}\|=0$ involving the inability to calculate Iagree. However, interviewed designers are experimented, so we consider they know the semantics they use and how to use it. Therefore, we do not reject these semantic cards, but we consider them apart. For the need of calculations, we set the value of $\|\mathrm{SD}\|$ to 0.1 in these cases.

$\forall i=[1 . . M]$; with $\mathrm{M}$ the total of selected semantics cards

$\forall j=[1 . . N]$; with $\mathrm{N}$ the total of designers evaluating the semantics $\mathrm{i}$

$$
\begin{aligned}
& \text { SDsport }_{i}=\sqrt{\frac{\sum_{j=1}^{N}\left(\text { Score }_{\text {sport }_{j}}-\overline{\text { Score }_{\text {sport }}}\right)^{2}}{N}} \quad \text { with } \quad \overline{\text { Score }_{\text {sport }}}=\frac{\sum_{j=1}^{N} \text { Score }_{\text {Sport }_{j}}}{N} \\
& \text { SDhealth }_{i}=\sqrt{\frac{\sum_{j=1}^{N}\left(\text { Score }_{\text {health }_{j}}-\overline{\text { Score }_{\text {health }}}\right)^{2}}{N}} \text { with } \overline{\text { Score }_{\text {health }}}=\frac{\sum_{j=1}^{N} \text { Score }_{\text {healt }_{j}}}{N} \\
& \|S D\|_{i}=\sqrt{\text { SDsport }_{i}^{2}+\text { SDhealth }_{i}^{2}} \forall N>1 ; \\
& \|S D\|_{i}=0.1 \quad \text { if } N=1 \text {; } \\
& \text { Iagree }_{i}=\frac{N}{\|S D\|_{i}} \forall N>1 \text {; }
\end{aligned}
$$

\section{Results}

Within this section, we present the results and the analyses based on a sample of six designers who participated in the interviews. All designers interviewed were French. All semantics and definitions given in the following sections are then translated from French.

The observed sample in this paper is only composed of men. We interviewed designers gathering at least 8 years of experiences to 23 years. All can be then considered as experts (Ahmed et al., 2003). Half of the 
sample is specialized on sports products, a third are global product designers and one participant is specialized on sport-health product.

\subsection{Sorting of a sport-health product card}

During the first part of the interview, we asked participants to sort pictures of sport, health and sporthealth products in order to obtain a visual overview of a sport-health product on which they can express thereafter. As results, we observed that 67 product pictures on the 85 presented were considered at least once as sport-health products and from these 67 product pictures, 35 were associated with sport-health product pictures by more than $50 \%$ of the studied sample.

\subsection{Definition of a sport-health product}

During the second step of the interview, we asked participants to give a definition of a sport-health product and to define a semantics. Definitions given by the studied sample are presented in Table 1 . All of them are translated from French. As first results, 50\% of the studied sample used "protection" to define a sport-health product (in bold in Table 1). Two designers mentioned a sport-health product as an "accessory" and as a "support" (in italic in Table 1). One designer stressed the "adaptability" to define a sport-health product (in bold and italic in Table 1).

Table 1. Definitions of a sport-health product according to interviewed designers

\begin{tabular}{|l|l|}
\hline Participant & \multicolumn{1}{c|}{ Given definition } \\
\hline 1 & $\begin{array}{l}\text { It is more about an accessory related to the practice of sport. I tend to tell myself if it's to } \\
\text { increase my protection it could be sport-health }\end{array}$ \\
\hline 2 & Sport-health, it's fake for now. It is consumable \\
\hline 3 & $\begin{array}{l}\text { Adaptability. When I think about sport-health product it's exactly that word that comes to my } \\
\text { mind. A sport-health product is either a support or adaptable. It is tailor-made. }\end{array}$ \\
\hline 4 & $\begin{array}{l}\text { This is for people who are afraid of hurting themselves with only the sports product. } \\
\text { It is all that is optional, to protect yourself. It is a piece of equipment that complements other } \\
\text { sports equipment and fits into the world of sport }\end{array}$ \\
\hline 5 & $\begin{array}{l}\text { It is a product preventing you that you are well in your practice. A Sport-Health product is related } \\
\text { to protection, support and respect in terms of physical integrity and in terms of compatibility. }\end{array}$ \\
\hline
\end{tabular}

In addition to these definitions, 63 semantics cards were associated at least once to a sport-health context. Among them, 9 semantic cards were written by designers (see right column in Table 2). From the 63 semantics cards, 26 were associated with sport-health context by more than $50 \%$ of the studied sample presented in bold in Table 2 below.

Table 2. Sport-health semantics selected by designers

\begin{tabular}{|lllll|l|}
\hline \multicolumn{2}{l}{ Words from sport and health semantics selected by designers } & & $\begin{array}{l}\text { Words generated by } \\
\text { designers }\end{array}$ \\
\hline Accessible & Delicate & Innovative & Natural & Simple & Adaptable \\
Aesthetic & Discreet & Intimacy & Neat & Soft & Consumable \\
Appealing & Dynamic & Intuitive & Original & Special & Fashion \\
Attractive & Ecologic & Isolating & Pleasant & Sporty & Human \\
Bold & Efficient & Light & Professional & Stable & Prevention \\
Casual & Ergonomic & Loose & Quality & Technologic & Security \\
Cheap & Expansive & Low grade & Quiet & Thick & Support \\
Clean & Formal & Mediocre & Resistant & Tight & Specific \\
Comfortable & Fragile & Modern & Rigid & Uncomfortable & Useful \\
Complex & Functional & Modest & Robust & Welcoming & \\
Cool & High grade & Narrow & Safe & & \\
\hline
\end{tabular}


According to the sorting of the semantics cards, we observe words like Safe and Resistant which are related to the "protection" aspect of given definition. Words like Accessible, Simple, Light, Comfortable are related to the "adaptable" aspect and words like Ergonomic or Tight evoke the "support" aspects of the given definitions. We notice some semantics translating the need to arouse consumer like Aesthetic, Appealing, Attractive, Modern or Pleasant and other semantics translating the idea of reliability like Efficient, Neat, Professional or Quality. However, arousal and reliability may be not specific to a sporthealth product, but common to all kinds of products. Based on definitions given by designers and results of the semantics cards sorting, we propose to define sport-health products as "an adaptable accessory supporting and protecting users during its practice of physical activities".

\subsection{Evaluation of sport-health semantics}

The last step of the interview consists on the evaluation of semantics on two 6-points scales in order to observe the influence of sport and health contexts of use on sport-health semantics. Table 3 presented below gathers selected and generated semantics cards with their related median scores on sport and health scales. We calculated median instead of means because of the use of ordinal scales.

Table 3. Sport and health medians of sport-health semantics

\begin{tabular}{|l|l|l|l|l|l|l|l|l|}
\hline Semantics & $M e_{\text {sport }}$ & $M e_{\text {health }}$ & Semantics & $M e_{\text {sport }}$ & $M e_{\text {health }}$ & Semantics & $M e_{\text {sport }}$ & $M e_{\text {health }}$ \\
\hline Accessible & 3.00 & 5.00 & High grade & 3.00 & 3.00 & Robust & 4.00 & 3.50 \\
\hline Aesthetic & 5.00 & 4.00 & Innovative & 4.00 & 4.00 & Safe & 3.50 & 5.00 \\
\hline Appealing & 5.00 & 1.00 & Intimacy & 1.00 & 4.50 & Simple & 3.50 & 3.00 \\
\hline Attractive & 5.00 & 4.00 & Intuitive & 4.00 & 2.50 & Soft & 5.00 & 5.00 \\
\hline Bold & 3.00 & 5.00 & Isolating & 2.50 & 5.00 & Special & 3.00 & 5.00 \\
\hline Casual & 4.00 & 1.00 & Light & 4.00 & 3.00 & Sporty & 4.00 & 2.50 \\
\hline Cheap & 4.00 & 2.00 & Loose & 2.00 & 4.00 & Stable & 5.00 & 5.00 \\
\hline Clean & 1.00 & 5.00 & Low grade & 4.00 & 2.50 & Technologic & 5.00 & 5.00 \\
\hline Comfortable & 3.50 & 3.50 & Mediocre & 5.00 & 3.00 & Thick & 2.00 & 5.00 \\
\hline Complex & 2.50 & 5.00 & Modern & 2.50 & 4.50 & Tight & 4.00 & 3.00 \\
\hline Cool & 4.00 & 2.00 & Modest & 2.00 & 3.00 & Uncomfortable & 1.00 & 5.00 \\
\hline Delicate & 2.00 & 4.00 & Narrow & 4.50 & 3.50 & Welcoming & 3.00 & 5.00 \\
\hline Discreet & 1.50 & 4.00 & Natural & 2.00 & 5.00 & Adaptable & 1.50 & 4.50 \\
\hline Dynamic & 4.50 & 2.50 & Neat & 4.00 & 4.00 & Consumable & 2.00 & 5.00 \\
\hline Ecologic & 1.00 & 5.00 & Original & 4.00 & 2.50 & Fashion & 4.00 & 1.00 \\
\hline Efficient & 4.50 & 4.00 & Pleasant & 2.50 & 3.00 & Human & 2.00 & 5.00 \\
\hline Ergonomic & 5.00 & 5.00 & Professional & 1.50 & 5.00 & Prevention & 4.00 & 2.00 \\
\hline Expensive & 5.00 & 2.00 & Quality & 5.00 & 5.00 & Security & 4.00 & 5.00 \\
\hline Formal & 5.00 & 2.00 & Quiet & 1.00 & 5.00 & Support & 1.00 & 5.00 \\
\hline Fragile & 4.00 & 1.00 & Resistant & 3.50 & 2.50 & Specific & 3.00 & 0.00 \\
\hline Functional & 4.00 & 4.00 & Rigid & 5.00 & 5.00 & Useful & 4.00 & 2.00 \\
\hline
\end{tabular}


In Table 4, we present each selected semantic card in regards with their Iagree value. The range of observed Iagree value varies from 0,50 to 5,20. We calculated the first quartile, the median and the third quartile of Iagree values (i.e.: $\mathrm{Q} 1=1,19 ; \mathrm{Me}=1,8 ; \mathrm{Q} 3=2,79$ ). Semantics presenting Iagree value lower than Q1 (first column in Table 4) present a high variability of score for a weak number of designers. As example Modest presents $\|S D\|$ modest $=4$ and Nmodest $=2$. In contrast, descriptors with a Iagree greater than Q3 (fourth column in Table 4) present a weak variability of scores with a high number of designers (like Innovative $\|S D\|$ innovative $=1,18$ and Ninnovative $=5$. These semantic descriptors appear then considered in a same way by designers of the sample. Column with Iagree $=100$ corresponds to the semantics evaluated by only one designer.

Table 4. Sport-health semantics categorization according to the lagree values

\begin{tabular}{|c|c|c|c|c|c|}
\hline & Q1< Iagree & $\mathrm{Me}<$ Iagree & & Iagree $=100$ & \\
\hline $\begin{array}{l}\text { Modest }(0.50) \\
\text { Sporty }(0.53) \\
\text { Pleasant (0.69) } \\
\text { Discreet (0.78) } \\
\text { Original (0.78) } \\
\text { Narrow (0.89) } \\
\text { Professional } \\
(0.94) \\
\text { Robust (0.94) } \\
\text { Delicate (1.00) } \\
\text { Aesthetic (1.16) }\end{array}$ & $\begin{array}{l}\text { Low grade } \\
(1.26) \\
\text { Efficient (1.26) } \\
\text { Intimacy (1.26) } \\
\text { Attractive (1.41) } \\
\text { Expensive } \\
(1.41) \\
\text { Ecologic (1.41) } \\
\text { Accessible } \\
(1.50) \\
\text { Welcoming } \\
(1.50) \\
\text { Safe (1.76) }\end{array}$ & $\begin{array}{l}\text { Light (1.84) } \\
\text { Adaptable (2.00) } \\
\text { Dynamic (2.00) } \\
\text { Resistant (2.00) } \\
\text { Ergonomic } \\
(2.50) \\
\text { Technologic } \\
(2.50) \\
\text { Quality (2.60) } \\
\text { Neat (2.60) } \\
\text { Functional (2.67) }\end{array}$ & $\begin{array}{l}\text { Complex (2.83) } \\
\text { Isolating (2.83) } \\
\text { Simple (2.83) } \\
\text { Modern (2.83) } \\
\text { Tight (3.00) } \\
\text { Comfortable } \\
\text { (3.50) } \\
\text { Natural (3.67) } \\
\text { Intuitive (3.70) } \\
\text { Innovative } \\
\text { (4.23) } \\
\text { Clean (5.20) }\end{array}$ & $\begin{array}{l}\text { Appealing } \\
\text { Bold } \\
\text { Casual } \\
\text { Cheap } \\
\text { Cool } \\
\text { Consumable } \\
\text { Fashion } \\
\text { Formal } \\
\text { Fragile } \\
\text { High grade } \\
\text { Human } \\
\text { Loose } \\
\text { Mediocre }\end{array}$ & $\begin{array}{l}\text { Prevention } \\
\text { Quiet } \\
\text { Rigid } \\
\text { Security } \\
\text { Soft } \\
\text { Special } \\
\text { Specific } \\
\text { Stable } \\
\text { Support } \\
\text { Thick } \\
\text { Uncomfortable } \\
\text { Useful }\end{array}$ \\
\hline
\end{tabular}

Based on these results, we mapped a sport-health semantic space with a bubble graph as illustrated in Figure 3. Abscissa and ordinate axes respectively correspond to the sport median and the health median. Both axes present a range from 0 to 5 corresponding to the min and the max of the score enable on semantics cards scales. The bubble size is proportional to the number of designers evaluating the semantics i. The upper left square $\left(M e_{\text {sport }}<2,5\right.$ and $\left.M e_{\text {health }}>2,5\right)$, area 1 , represents the area where sport-health semantics is related to health context of use. In contrast, we can observe sport-health semantics linked to sport context of use in area $3\left(M_{\text {sport }}>2,5\right.$ and $M e_{\text {health }}<$ 2,5). Thus, semantic descriptors like Clean, Professional or Adaptable appear more adapted to define a sport-health product intended to health context and words like Expensive, Fashion or Cool appear more suitable to define sport-health product intended to sport context. Concerning the area $2\left(M e_{\text {sport }}\right.$ $>2,5$ and $M e_{\text {health }}>2,5$ ), it represents sport-health semantics with weak influence from context of use. Semantics in this last area like Innovative, Functional, Neat or Ergonomic appear adapted to convey meanings for a sport-health product context. 


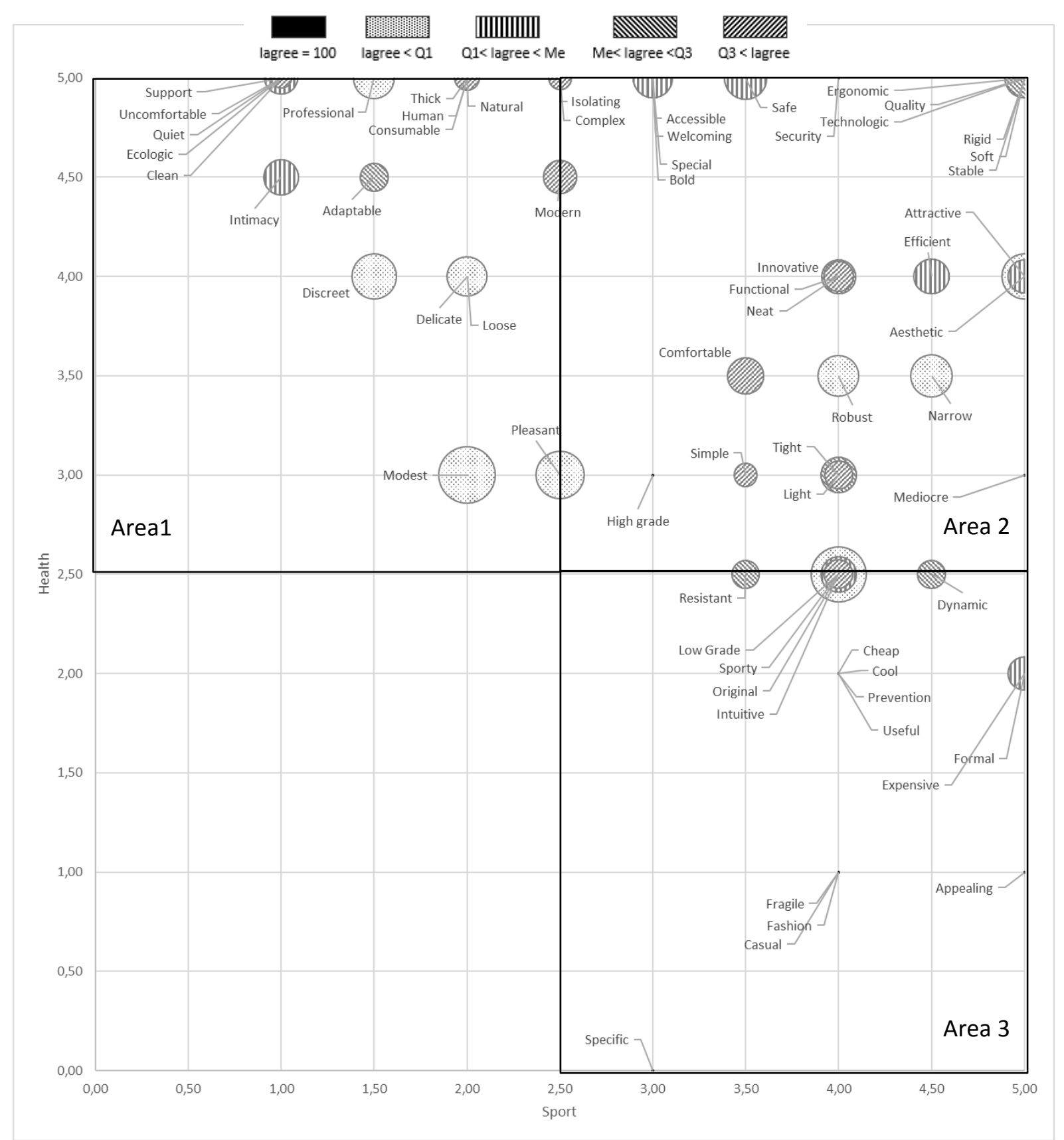

Figure 3. Sport-health semantic perceptual map based on designers' interviews

\section{Conclusion and discussion}

In this paper, we presented our approach to observe the influence of sport and health contexts of use on sport-health semantics. With the participation of 6 designers who are experts in their fields, we observe the following results:

- A sport-health product could be defined as: "an adaptable accessory supporting and protecting users during its practice of physical activities"

- 65 semantic descriptors appear adapted to sport-health semantics according to interviewed designers.

- A visualization of the sport and health "weight" of each sport-health semantics identified by designers. 
However, the size of the studied sample may be a limit in this paper. Indeed, some words were selected only once, or were evaluated by several designers in an opposite way. For this reason, we decided to apply an agreement measure. To go further, we can observe in literature various criteria applicable for this purpose like reliability criteria. Among them, the $\alpha$-Krippendorff appears the most promising. Indeed, it can be used with ordinal values, it works even with missing values and it is adapted to all sample sizes (Hayes and Krippendorff, 2007; Vaucher, 2017). However, in our case, 0 value within the evaluation conflicts with "0" as empty answer, making the Krippendorff coefficient non usable. For further interviews we will take this limit into account by changing the values in the scales.

As aforementioned, some semantics were evaluated only once. We choose to keep these semantics because all interviewed designers were experts. Therefore, we assume that words they used and selected are the results from their knowledge experienced for more than 20 years concerning some of them. However, a way to refine this map and go further is to conduct more interviews. Furthermore, the designers' sample interviewed is only composed of men more specialized in sport products. We may enhance the sample with other designers' profile, like women or designers specialized in health product design in order to better refine this map.

In this paper, we focus on the designer point of view. However, in Human Centred Design approach, there is a known issue concerning the difference of perception between designers and consumers (Crilly et al., 2008; Desmet and Hekkert, 2007; Khalaj and Pedgley, 2014). It may then be interesting to reproduce the interviews with consumers and confront the results.

Finally, this work is part of a more global research. Based on these results, we aim to link the obtained semantic perceptual map to product attributes (color, shapes, material, ...) in order to understand and define not only the meaning of a sport-health product but also its appearance.

We believe that these results will help designers in their tasks especially in sport and/or health product fields. Indeed, the visualization of semantics regarding products contexts of use may help them to take decisions. In the earlier phases of the design process, designers define the direction of the product development. These results may help them choose the right meaning to convey for the product development and be used as guide during the design process. In addition, these results can be useful to validate and to correct the product development. Indeed, while confronting the product to consumers and/or users, designers can observe if it fits to the product realm targeted in the earlier phases of the design process.

\section{References}

Ahmed, S., Wallace, K.M. and Blessing, L.T.M. (2003), "Understanding the differences between how novice and experienced designers approach design tasks", Research in Engineering Design, Springer Verlag, Vol. 14 No. 1 , pp. 1-11.

Bouchard, C. and Omhover, J.F. (2016), "Supporting early design through conjoint trends analysis methods and the TRENDS system", Collaboration in Creative Design: Methods and Tools. Available at: https://doi.org/10.1007/978-3-319-29155-0_4

Chitturi, R. (2009), "Emotions by design: A consumer perspective”, International Journal of Design.

Crilly, N., Maier, A. and Clarkson, P.J. (2008), "Representing artefacts as media: Modelling the relationship between designer intent and consumer experience", International Journal of Design.

Demirbilek, O. and Sener, B. (2003), "Product design, semantics and emotional response", Ergonomics. Available at: https://doi.org/10.1080/00140130310001610874

Desmet, P. and Hekkert, P. (2007), "Framework of product experience", International Journal of Design.

Green, A. and Chattaraman, V. (2019), "Creating an affective design typology for basketball shoes using kansei engineering methods", Advances in Intelligent Systems and Computing, Vol. 774, Springer Verlag, pp. 355-361.

Guo, Y., Yang, M. and Zhou, M. (2018), "Persuasive semantics of aging health products based on AHP and Kansei engineering", Advances in Intelligent Systems and Computing, Vol. 585, Springer Verlag, pp. 337-345.

Hassenzahl, M. (2010), "Experience Design: Technology for All the Right Reasons", Synthesis Lectures on Human-Centered Informatics, Morgan \& Claypool Publishers LLC, Vol. 3 No. 1, pp. 1-95.

Hayes, A.F. and Krippendorff, K. (2007), "Answering the Call for a Standard Reliability Measure for Coding Data", Communication Methods and Measures, Informa UK Limited, Vol. 1 No. 1, pp. 77-89.

von Hippel, E. (2009), "Democratizing Innovation: The Evolving Phenomenon of User Innovation", International Journal of Innovation Science, Vol. 1 No. 1, pp. 29-40. 
INSEP and Ministère de la ville de la jeunesse et des sports. (2015), "La Pratique Des Activités Physiques et Sportives En France”, edited by Canneva, H.La Pratique Des Activités Physiques et Sportives En France, INSEP-Éditions. Available at: https://doi.org/10.4000/books.insep.796

Jordan, P.W. (2003), Designing Pleasurable Products: An Introduction to the New Human Factors, Taylor \& Francis e-Library.

Khalaj, J. and Pedgley, O. (2014), "Comparison of semantic intent and realization in product design: A study on high-end furniture impressions", International Journal of Design.

Kongprasert, N. et al. (2008), "How to design and process brand identity through an integrated innovative approach", 2008 IEEE International Conference on Industrial Engineering and Engineering Management, IEEM 2008. Available at: https://doi.org/10.1109/IEEM.2008.4737970.

Krippendorff, K. (2005), “The Semantic Turn: A New Foundation for Design - CRC Press Book", edited by Press, C., 1st ed. Available at: https://www.crcpress.com/The-Semantic-Turn-A-New-Foundation-forDesign/Krippendorff/p/book/9780415322201 (accessed 26 October 2019).

Krippendorff, K. and Butter, R. (1984), "Product Semantics: Exploring the Symbolic Qualities of Form", Innovation, Vol. 3 No. 2, pp. 4-9.

Lallemand, C. and Gronier, G. (2018). "Méthodes de Design UX - C.Lallemand", G.Gronier - 2ème Édition Librairie Eyrolles, edited by Eyrolles, 2eme ed., available at: https:/www.eyrolles.com/Informatique/ Livre/methodes-de-design-ux-9782212673982/ (accessed 24 September 2019).

Lüthje, C. (2004), "Characteristics of innovating users in a consumer goods field: An empirical study of sportrelated product consumers", Technovation, Elsevier Ltd, Vol. 24 No. 9, pp. 683-695.

Marsac, E., Kim, K.O. and Takatera, M. (2018), “Japanese-French tastes in simulated women's sportswear tshirts", International Journal of Clothing Science and Technology, Emerald Group Publishing Ltd., Vol. 30 No. 5, pp. 641-656.

Masagué, S.G. and Macià, J.L. (2015), "User-Centered Design for Emotion. A Case Study in Wellness Products", In: Complex Systems Design \& Management, Springer International Publishing, Cham, pp. 193-206.

Millet, A. et al. (2019), "Definition of a 'Sport-Health' Semantic Space”, Proceedings of the Design Society: International Conference on Engineering Design, Cambridge University Press (CUP), Vol. 1 No. 1, pp. 3841-3850.

Nagamachi, M. (1989), "Kansei engineering approach to automotive", Journal of the Society of Automotive Engineers of Japan, Vol. 43, pp. 94-100.

Norman, D.A. (2007). Emotional Design: Why We Love (or Hate) Everyday Things, edited by UK.

Osgood, C.E. (1952), “The nature and measurement of meaning”, Psychological Bulletin, Vol. 49 No. 3, pp. 197-237.

Petiot, J.F. and Yannou, B. (2004), "Measuring consumer perceptions for a better comprehension, specification and assessment of product semantics", International Journal of Industrial Ergonomics, Vol. 33 No. 6, pp. 507-525.

Schütte, S. et al. (2008), “Affective meaning: The Kansei Engineering approach”, Product Experience, pp. 477-496.

Shieh, M.D. and Yeh, Y.E. (2015), “A comparative study on perceptual evaluations of sports shoe exterior", Color Research and Application, John Wiley and Sons Inc, Vol. 40 No. 2, pp. 178-193.

Stefanyshyn, D.J. and Wannop, J.W. (2015), "Biomechanics research and sport equipment development", Sports Engineering, Springer-Verlag London Ltd, Vol. 18 No. 4, pp. 191-202.

Trujillo, J.L.H., Aviñó, A.M.i. and Millán, C.L. (2017), "User Evaluation of Neonatology Ward Design: An Application of Focus Group and Semantic Differential", Health Environments Research and Design Journal, SAGE Publications Inc., Vol. 10 No. 2, pp. 23-48.

Vaucher, P. (2017), “Fiabilité d'un test, d'une mesure ou d'une procédure d'évaluation”, Mains Libres, No. June, pp. 49-55.

Wang, W.M. et al. (2018), "Extracting and summarizing affective features and responses from online product descriptions and reviews: A Kansei text mining approach", Engineering Applications of Artificial Intelligence, Elsevier Ltd, Vol. 73, pp. 149-162.

Wilson, N., Thomson, A. and Riches, P. (2017), "Development and presentation of the first design process model for sports equipment design", Research in Engineering Design, Springer London, Vol. 28 No. 4, pp. 495-509. 